\title{
BRUCELOSE EM BOVINOS COM BURSITE CERVICAL DIAGNOSTICADA EM ABATEDOURO SOB INSPEÇÃO FEDERAL ${ }^{1}$
}

\author{
BRUCELOSIS IN CATTLE WITH SUPRASPINOUS BURSITIS DIAGNOSED \\ IN AN ABATTOIR UNDER FEDERAL INSPECTION
}

\section{Laerte Pereira de Almeida ${ }^{2}$ Dênio Oliveira Reis ${ }^{3}$ Pedro Manuel Leal Germano ${ }^{4}$}

\section{RESUMO}

Estudo epidemiológico tipo caso-controle realizado em Uberlândia, Minas Gerais (MG), Brasil, pesquisou a ocorrência de brucelose em bovinos com bursite cervical, abatidos no período de agosto de 1993 a julho de 1994. O diagnóstico sorológico de brucelose foi realizado mediante a prova de soroaglutinação rápida em placa. Os casos de bursite foram identificados por técnico do Serviço de Inspeção Federal (SIF), com base em características morfológicas, previamente padronizadas. Para a determinação da "Razão de Odds" e do risco atribuível entre bursite e brucelose, utilizaram-se 30 animais com o quadro e, como controle, 90 bovinos sem a patologia. Dos animais com bursite, 13,3\% eram brucélicos, contra 5,6\% do grupo controle $(P=0,115)$. Dentre aqueles com brucelose $e$ bursite, as bolsas continham fibrina (40,0\%) e projeções digitiformes (33,3\%); apenas nas bursites dos sorologicamente negativos encontraram-se presença de pus, de nódulos e de líquido viscoso. A "Razão de Odds" encontrada entre brucelose e bursite foi da ordem de 2,61, não sendo demonstrado associação entre bursite cervical $e$ sorologia positiva para brucelose $(P>0,05)$. No âmbito da Saúde Pública e ocupacional, sugere-se a atenção de técnicos e profissionais, visando diminuir o risco de infecção e evitar contaminação de carcaças, equipamentos e instalações.

Palavras-chave: bursite cervical bovina, brucelose, zoonoses.

\section{SUMMARY}

Epidemiological study case-control type carried out in Triângulo abattoir in the city of Uberlandia in the State of Minas Gerais, Brazil, has identified the ocorrence of brucelosis in bovine with supraspinous bursitis, slaughtered from August, 1993 to July, 1994. To diagnose brucelosis "Rapid Agglutination" test was performed on plate with the padronizated antigen count considered positive over 100. The bursas examined were identified by technicians of the Federal Inspection Service based on the presence of ten standardized morphological characteristics. Using the casecontrol design, 30 animals identified as having supraspinous bursitis were compared with 90 animals randomly selected, without bursitisbut with other characteristics (sex, background, lot, conformation) similar to those affected. All animals were, then, tested for brucelosis. Within the animals with bursitis, $13.33 \%$ were found to have brucelosis against $5.56 \%$ in the control group $(P=0.115)$. The presence of pus, nodules and viscous fluid was found only among animals who tested negative for brucelosis. The odds ratio found between brucelosis and supraspinous bursitis was $2.61(P>0.05)$. As a conclusion it's suggested attention of technicians and profesionals employed in slaughter houses aiming to reduce the risk of human infection, as well as of carcasses, equipment and installations contamination.

Key words: bursitis supraspinous bovine, brucelosis, zoonosis.

\section{INTRODUÇÃO}

As bursites da cernelha de bovinos são de difícil visualização à inspeção sanitária antemorte, sendo de pouco valor a tentativa de separação de animais suspeitos (LANGENEGGER $\boldsymbol{e t}$ al., 1975). É no exame pós-morte, realizado nos frigoríficos por inspetores do Serviço de Inspeção Federal (SIF), que as bursites podem ser diagnosticadas mediante exames macroscópicos.

LANGENEGGER et al. (1975) alertam sobre a possibilidade das bursas, quando sede de processos inflamatórios, romperem-se durante os procedimentos de manipulação, executados tanto pelos técni-

\footnotetext{
${ }^{1}$ Extrato de Tese de Doutorado intitulada "Bursite cervical em Bovinos: Avaliação da Brucelose como fator de risco". Apresentada à Faculdade de Saúde Pública da Universidade de São Paulo.

${ }^{2}$ Médico Veterinário, DS, Professor Adjunto, Departamento de Nutrição e Saúde, Universidade Federal de Viçosa-(UFV). Avenida PH Rolfs, s/n- Campus Universitário. 36571-000- Viçosa-Minas Gerais. E-mail: lalmeida @ mail.ufv.br. Autor para correspondência.

${ }^{3}$ Médico Veterinário, Esp., Professor Titular, DVT, Universidade Federal de Uberlândia-MG.

${ }^{4}$ Médico Veterinário, DS, Professor Titular, FSP, Universidade de São Paulo. 
cos quanto pelos inspetores do SIF, provocando o eventual extravasamento do conteúdo das bolsas mucosas e a conseqüente infecção do operador por contaminação do equipamento e das instalações.

Entre os agentes sépticos, responsabilizados pela etiologia das bursites, estão as brucelas, devido à afinidade peculiar por bolsas mucosas (PARDI $\boldsymbol{e} t$ al., 1956). As primeiras referências sobre a presença da Brucella sp em higromas carpais de bovinos são da década de 1930 (BOYD et al., 1930; MAGNUSSON, 1933). Posteriormente, vários autores isolaram Brucella abortus a partir desses tipos de higromas (DELEZ, 1934; HUMPHREYS \& MOORE, 1941; JOHNSON \& WEED, 1954), bem como de bursites com localização cervical (FERAUGE,1942; GILYARD \& GILYARD, 1943; LANGENEGGER $\boldsymbol{e}$ al., 1975).

COID \& VAUGHAN (1957), em estudo realizado com bovinos de leite, mostraram que a incidência de higroma carpal em bovinos, infectados em condições experimentais com Brucella abortus, não foi significativamente maior do que o verificado em animais não infectados. Não houve, ainda, diferença entre a ocorrência de higromas em animais vacinados, uma ou mais vezes, com Brucella vacinal e animais não vacinados. De acordo com RUNNELLS et al. (1976), apesar da Brucella sp ser freqüentemente isolada dessas patologias, não se demonstrou que ela seja a causadora das alterações supurativas.

Os estudos sobre bursite não são numerosos, notadamente, os que se referem a bovinos e, ainda, em menor número, os que tratam da bursite cervical. Deve-se destacar que a grande maioria desses trabalhos refere-se a relatos de casos objetivando o isolamento do agente brucélico dos higromas, ou a realização de exames sorológicos para brucelose, apenas, nos animais com a patologia. Em alguns desses trabalhos (LANGENEGGER et al., 1975; FERAUGE, 1942), conseguiu-se isolar o agente brucélico ou comprovou-se a sorologia positiva de animais com bursite, reconhecendo-se o envolvimento da Brucella sp nessa patologia. Contudo, esses estudos não mostraram evidências conclusivas de que a Brucella sp estivesse associada à lesão em bovinos e, em particular, à bursite cervical, pois foram estudos referentes a casos da patologia, sem utilização de grupo controle.

A partir dos aspectos mencionados, o presente trabalho objetivou investigar a ocorrência de brucelose em bovinos com bursite cervical diagnosticada em frigorífico sob inspeção federal, mediante à realização de estudo observacional, tipo Caso-Controle (BRESLOW \& DAY, 1980), contribuindo, assim, para a elucidação de aspectos epidemiológicos e fornecendo subsídios para a área da saúde ocupacional, dado o risco de exposição dos trabalhadores em frigoríficos.

\section{MATERIAL E MÉTODOS}

O estudo foi conduzido no Frigorífico Triângulo do município de Uberlândia, Minas Gerais no período de agosto de 1993 a julho de 1994. O abate nesse estabelecimento, predominantemente de bovinos procedentes da microregião triangulina e do Estado de Goiás, é realizado três vezes por semana, com média de 200 cabeças por jornada de trabalho. Outros estados, eventualmente, enviam animais para o abate.

Foi considerado como portador da patologia e, conseqüentemente, incluído na amostragem, o animal que durante o abate, examinado por inspetor do Serviço de Inspeção Federal (SIF) do Ministério da Agricultura, apresentou alterações na bolsa mucosa da cernelha caracterizadas, pelo aspecto morfológico, como bursite. No período de estudo, foram diagnosticados 40 casos de bursite da cernelha. Desses casos, 30 foram utilizados para o estudo Caso-Controle e 10 tiveram de ser descartados, por não ter sido possível o acompanhamento dos animais na linha de inspeção com conseqüente perda de informações. Para cada animal com bursite detectado, foram selecionados 3 animais controles, sem bursite, observando-se o mesmo sexo, compleição física, faixa etária e unidade de produção.

O diagnóstico de bursite, realizado durante a inspeção de carcaças, foi feito através da inspeção, rotineira e sistemática, dos ligamentos cervicais, em cada animal abatido. Realizando-se incisões entre a terceira e a quarta vértebras torácicas para melhor exposição desses ligamentos. Após diagnosticada a bursite, suas características morfológicas foram lançadas em ficha padronizada, previamente testada, onde constavam 10 tópicos a serem considerados. O diagnóstico e a caracterização da bursite foram realizados pelo mesmo inspetor do SIF.

Foram colhidas amostras de sangue dos animais diagnosticados com bursite da cernelha e de seus respectivos controles (1:3). A colheita foi realizada durante a inspeção pós-abate, quando os animais suspeitos de bursite foram submetidos à inspeção final; o sangue foi colhido a partir dos grandes vasos por flexionamento dos membros anteriores. As amostras de sangue, após colhidas, foram colocadas em frascos estéreis, dispostos inclinadamente para favorecer a retração do coágulo e conseqüente dessoração à temperatura ambiente. Posteriormente, foram levadas para o laboratório onde foram realizadas as provas sorológicas para deteção de aglutininas antibrucela (OMS, 1968).

A técnica usada para a realização dos exames sorológicos para brucelose foi a de Soroaglutinação Rápida em Placa, com antígenos padronizados fornecidos pelo Ministério da Agricultura, elaborados 
a partir da amostra 119-3 e na concentração de $11 \%$. Sendo considerados positivos, para a infecção brucélica, os soros com títulos iguais ou superiores a 100, (OMS, 1968).

Os dados, armazenados em Banco de Dados, foram analisados por meio do software EPIINFO 6.04. Sendo calculados a Razão de Odds e o respectivo intervalo de confiança de $95 \%$ entre os resultados da infecção brucélica e bursite da cernelha, verificando-se a presença de associação significativa por meio do teste exato de Fisher, com alfa igual a 5,0\%. Para análise dos resultados concernentes à morfologia das bursites da cernelha, cada característica morfológica foi avaliada, separadamente, frente à condição sorológica para brucelose. Com base na "Razão de Odds" e na frequiência de reações sorológicas antibrucela, registrada em animais abatidos no Frigorífico Triângulo, calculou-se o Risco Atribuível na população, utilizando-se a fórmula de Levin (BRESLOW \& DAY, 1980).

\section{RESULTADOS}

Observando a tabela 1 , verifica-se que dos animais que apresentaram bursite, $13,33 \%$ estavam sorologicamente positivos para a brucelose, enquanto $5,55 \%$ dos animais sem bursite (controles) mostraram resultado sorológico positivo. Essas proporções, quando analisadas mediante a prova de Fisher, não mostraram diferenças significativas $(\mathrm{P}=0,115)$.

A partir dos dados dispostos na tabela 2 , foi calculado a "Razão de Odds", obtendo-se 2,61(0,84$7,70)$ como resultado, estatisticamente não significante $(\mathrm{P}>0,05)$. Com os valores da "Razão de Odds" $(2,61)$ e

Tabela 1 - Bovinos abatidos no Frigorífico Triângulo segundo os resultados do exame da bursa cervical e da prova sorológica para brucelose. Uberlândia, Minas Gerais. Agosto/93 a julho/94

\begin{tabular}{lll}
\hline Exames da Bursa & Prova sorológica & Total \\
Cervical & & \\
\hline
\end{tabular}

\begin{tabular}{|c|c|c|c|c|c|c|}
\hline & \multicolumn{2}{|c|}{ Positivos } & \multicolumn{2}{|c|}{ Negativos } & \multirow[b]{2}{*}{$\mathrm{N}^{\circ}$} & \multirow[b]{2}{*}{$\%$} \\
\hline & $\mathrm{N}^{\circ}$ & $\%$ & $\mathrm{~N}^{\circ}$ & $\%$ & & \\
\hline Com bursite & 04 & 13,3 & 26 & 86,6 & 30 & 100,0 \\
\hline Sem bursite & 05 & 5,5 & 85 & 94,4 & 90 & 100,0 \\
\hline Total & 09 & 7,5 & 111 & 92,5 & 120 & 100,0 \\
\hline
\end{tabular}

Tabela 2 - "Razão de Odds" de bursite cervical em bovinos segundo a condição sorológica para brucelose. Uberlândia, MG, Agosto/93 a Julho/94.

\begin{tabular}{|c|c|c|}
\hline $\begin{array}{l}\text { Resultado Sorológico } \\
\text { para Brucelose }\end{array}$ & Exames da Bursa Cervical & $\begin{array}{c}\text { "Razão de Odds" } \\
\text { (IC 95\%) }\end{array}$ \\
\hline
\end{tabular}

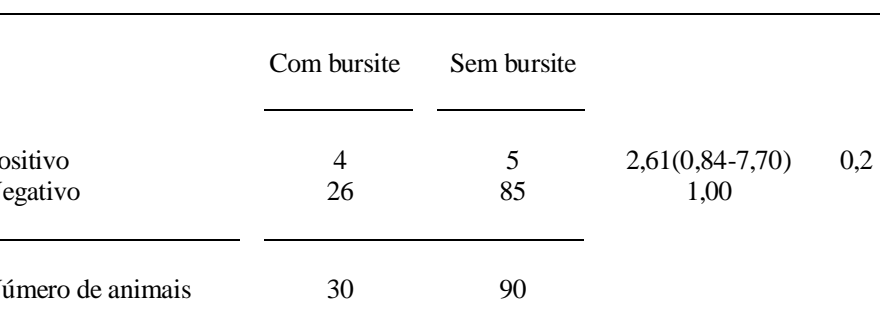

da freqüência de ocorrência de brucelose em bovinos abatidos no Frigorífico Triângulo $(5,14 \%)$, determinou-se o Risco Atribuível na população, o qual foi da ordem de $7,64 \%$.

As características morfológicas de bursites cervicais, em bovinos, ao serem confrontadas com os resultados sorológicos dos respectivos animais mostraram que a presença de fibrina $(40,0 \%)$, de projeções digitiformes $(33,3 \%)$ e de líquido amarelado $(25,0 \%)$ foram as mais frequientes em animais soropositivos para a infecção brucélica; enquanto que características como a presença de pus, a presença de nódulos e de líquido viscoso foram observadas, exclusivamente, nos animais com sorologia negativa (Tabela 3 ).

\section{DISCUSSÃO}

A pesquisa realizada em Frigorífico sob Uberlândia, Minas Gerais, durante um período de 12 meses, com bovinos provenientes de 4 estados e 50 municípios, possibilitou alguns resultados, que são a seguir discutidos.

Com base na tabela 1 , comprova-se a ausência de associação significante $(\mathrm{P}=0,115)$ entre os resultados positivos da prova sorológica para brucelose e o número de animais com bursite. "A Razão de Odds", calculada a partir da tabela 2, demonstra que apesar das bursites poderem ser encontradas com maior probabilidade nos animais com infecção por brucelose - até 2,6 vezes - o resultado não é significativo $(\mathrm{P}=0,22)$.

Essas observações estão coerentes com a taxa obtida mediante o cálculo do Risco Atribuível na População, quando ficou evidenciado que os casos de bursite da cernelha em bovinos seriam reduzidos em apenas $7,64 \%$, caso a infecção por brucelose fosse erradicada do rebanho. O que, também, foi confirmado por RUNNELLS et al. (1976), ao constatarem não ter havido diminuição na incidência de fístulas e artrites em bovinos da Noruega, após a erradicação da brucelose.

Ciência Rural, v. 30, n. 2, 2000. 
Tabela 3 - Bovinos abatidos no Frigorífico Triângulo segundo as características morfológicas encontradas em casos de bursite da cernelha e os resultados sorológicos para brucelose. Uberlândia, Minas Gerais. Agosto/93 a julho/94.

\begin{tabular}{|c|c|c|c|c|c|c|}
\hline \multirow{3}{*}{$\begin{array}{l}\text { Características } \\
\text { morfológicas }\end{array}$} & \multicolumn{4}{|c|}{ Sorologia para brucelose } & \multicolumn{2}{|c|}{ Totais } \\
\hline & \multicolumn{2}{|c|}{ Positivo } & \multicolumn{2}{|c|}{ Negativo } & \multirow[b]{2}{*}{$\mathrm{N}^{\circ}$} & \multirow[b]{2}{*}{$\%$} \\
\hline & $\mathrm{N}^{\circ}$ & $\%$ & $\mathrm{~N}^{\circ}$ & $\%$ & & \\
\hline Presença de fibrina & 02 & 40,00 & 03 & 60,00 & 05 & 100,00 \\
\hline Projeções digitiformes & 02 & 33,34 & 04 & 66,66 & 06 & 100,00 \\
\hline Líquido amarelado & 01 & 25,00 & 03 & 75,00 & 04 & 100,00 \\
\hline Bolsa ovalada & 02 & 20,00 & 08 & 80,00 & 10 & 100,00 \\
\hline Vascularização intensa & 03 & 17,65 & 14 & 82,35 & 17 & 100,00 \\
\hline Parede espessa & 02 & 15,39 & 11 & 84,61 & 13 & 100,00 \\
\hline Presença de líquido & 01 & 16,67 & 05 & 83,33 & 06 & 100,00 \\
\hline Presença de pus & 00 & 0,00 & 11 & 100,00 & 11 & 100,00 \\
\hline Presença de nódulos & 00 & 0,00 & 16 & 100,00 & 16 & 100,00 \\
\hline Líquido viscoso & 00 & 0,00 & 03 & 100,00 & 03 & 100,00 \\
\hline
\end{tabular}

Deve-se destacar que a ausência de associação entre infecção brucélica e bursite concorda com os resultados obtidos em estudo experimental de COID \& VAUGHAN (1957), mas discorda dos resultados obtidos em estudo observacional, transversal, realizado por MCDERMOTT et al. (1987).

$\mathrm{Na}$ ausência de associação significante entre diagnóstico sorológico da brucelose e bursite da cernelha, a maioria das patologias da bursa observadas neste estudo não apresentava origem brucélica. Portanto, presume-se que as características morfológicas observadas com maior frequiência na tabela 3 não sejam sugestivas de bursite brucélica. $\mathrm{Na}$ realidade, dado o reduzido número de casos de bursite em animais com brucelose, torna-se difícil caracterizar morfologicamente essas patologias.

A análise comparativa, entre os dados apresentados nas tabelas 2 e 3 , reforça a mencionada hipótese. Assim, as características morfológicas de bursites da cernelha com maior probabilidade de serem encontradas, quando os animais são sorologicamente positivos para brucelose, pela técnica de Soroaglutinação em Placa, seriam: presença de fibrina; presença de projeções digitiformes. Enquanto que as características morfológicas de bursite da cernelha, que mais provavelmente sugeririam tratar-se de animais sorologicamente negativos para a brucelose, seriam: presença de pus; presença de nódulos.

MAGNUSSON, H. Le bacille de L'avortement de Bang et les hygromas des bovidés. Ver Gén Med Vét, v.42, p.465-485, 1933.
PARDI $\boldsymbol{e t}$ al. (1956), em estudo realizado no Frigorífico de Barretos, São Paulo, corroboram, pelo menos em parte, a hipótese sugerida ao descreverem algumas características morfológicas das bursites estudadas. Relatam a presença de pus associado com o não isolamento de Brucella e com resultados sorológicos negativos ou títulos baixos à prova de Soroaglutinação Rápida em Placa. Esses autores relatam, ainda, a presença de "nódulos parasitários necrosados, outros calcificados", sugerindo tratar-se de bursites associadas a outras causas que não brucelose. Outros autores, como LANGENEGGER et al. (1975), em estudo realizado no Frigorífico do Rio de Janeiro, com animais de abate, encontraram 14 animais soropositivos para brucelose entre 17 casos de bovinos com bursite cervical. Estes casos apresentaram como características morfológicas predominantes a presença de fibrina e líquido seroso, enquanto o pus esteve ausente em todos os casos relatados, o que vem reforçar, ainda mais, o achado do estudo realizado em Uberlândia.

Os resultados obtidos neste estudo mostraram que, apesar da ausência de associação significativa entre a bursite cervical bovina e sorologia positiva para a brucelose, $13,3 \%$ dos bovinos com bursite eram brucélicos, demonstrando o potencial do tecido afetado por bursites como via de transmissão da infecção brucélica a trabalhadores e contaminação de outras carcaças, equipamentos e instalações em estabelecimentos de abate de bovinos.

\section{REFERÊNCIAS BIBLIOGRÁFICAS}

BOYD, W.L., DELEZ, A. L., FITLH, C. P. The association of Bacterium abortus Bang with hygroma of the knee of cattle. Cornell Vet, v.20, p.263-268, 1930.

BRESLOW, N.E., DAY, N.E. Statistical methods in cancer research- The analysis of case-control studies. Lyon : IARC, 1980. 340p.

COID, C.R., VAUGHAN, L.C. Incidence of carpal hygromas in dairy cattle infected with Brucella abortus and maintained in an isolation compound. J Comp Pathol, v.67, p.53-56, 1957.

DELEZ, A.L. Brucella abortus in the serous effusion of the hipjoint of a cow. J Am Vet Med Assoc, v.85, p.405-406, 1934.

FERAUGE, M.A. La bursite de l'encolure chez la bête bovine. Ann Méd Vét, Brussels, v.86, p.225-229, 1942.

GILYARD, A.T., GILYARD, R.T. Vaccinal therapy in fistulous withers. J Am Vet Med Assoc, v.102, p.204-207, 1943.

HUMPHREYS, F.A., MOORE, T. Studies in relation to Brucella abortus infection. II. On the occurrence of the organism in the serous swellings or hygromata. Canad J Comp Med, v.5, p.5$20,1941$.

JOHNSON, E.W.Jr., WEED, L.A. Brucellar bursitis. J Bone Joint Surg v.36A, n.1, p.133-139, 1954

LANGENEGGER, J., SECCHIN, H., BAPTISTA, A.M. Bursites brucélicas na cernelha de bovinos de abate e cuidados sanitários no matadouro. Pesq Agropec Bras Ser Vet, v.10, p.45-49, 1975.

MCDERMOTT, J.J., DENG, K.A., JAYATILEKA, T.N. et al. A cross-sectional cattle disease study in Kongor rural council, southern Sudan. II. Brucellosis in cows: associated factors, 
impact on production and disease control considerations. Prev Vet Med, v.5, n.2, p.125-132,1987.

ORGANIZACIÓN MUNDIAL DE LA SALUD. Técnicas de seroaglutinación: Brucelosis. Buenos Aires: CEPANZO, 1968. 19p. Nota técnica, 2 - Rev. 1.

PARDI, M.C., ROCHA, U.F., SALIBA, A. Brucella abortus (Bang) como causa de bursite cervical em bovinos. Bol Soc Bras Med Vet, v.24, p.25-34, 1956
RUNNELlS, R.A., MONLUX, W.S., MONLUX, A.W. Princípios de patologia veterinária-anatomia patológica. México : $\mathrm{DF}$ : C.E.C.S.A., 1976. 431p.

Ciência Rural, v. 30, n. 2, 2000. 